\title{
Evaluation of reference values of standard semen parameters in fertile Egyptian men
}

\author{
H. Zedan, S. Ismail, A. Gomaa, R. Saleh, R. Henkel and A. Agarwal
}

\section{Summary}

The reference values of human semen, published in the WHO's latest edition in 2010, were lower than those previously reported. The objective of this study was to evaluate reference values of standard semen parameters in fertile Egyptian men. This cross-sectional study included 240 fertile men. Men were considered fertile when their wives had recent spontaneous pregnancies with time to pregnancy (TTP) $\leq 12$ months. The mean age of fertile men was $33.8 \pm 0.5$ years (range $20-55$ years). The 5 th percentiles (95\% confidence interval) of macroscopic semen parameters were $1.5 \mathrm{ml}$ for volume and 7.2 for $\mathrm{pH}$. The $5^{\text {th }}$ percentiles of microscopic parameters were 15 million/ml for sperm concentration, 30 million per ejaculate for total sperm count, $50 \%$ for total motility, $40 \%$ for progressive motility, $62 \%$ for vitality, $4 \%$ for normal sperm forms and $0.1 \mathrm{million} / \mathrm{ml}$ for seminal leucocyte counts. In conclusion, fertile Egyptian men had higher reference values of sperm total motility, progressive motility and vitality, and lower reference values for total sperm counts as compared to those determined by the latest edition of the WHO laboratory manual in 2010. Other semen parameters were identical to those defined by the WHO 2010 manual.

\section{1 | Introduction}

Standard procedures of semen analysis are routinely used in most laboratories for initial evaluation of male fertility potential. These procedures include initial macroscopic examination of semen appearance, liquefaction, volume, viscosity and $\mathrm{pH}$; and microscopic investigation of sperm concentration, motility and morphology; and assessment of seminal leucocytes and immature germ cells (WHO, 2010). Despite its weaknesses as a diagnostic tool, standard semen analysis allows for detection of remarkable cases of infertility such as azoospermia (Saleh et al., 2002). In addition, with repetitively abnormal semen analyses results, men can be diagnosed as infertile and an approximate prognosis can be given.

The methods of human semen evaluation are provided by the WHO, which periodically releases manuals including specific protocols and reference standards (Esteves, 2014). The WHO published its updated $5^{\text {th }}$ edition of the laboratory manual for the examination of human semen in late 2010. This latest edition of the manual established reference values derived from data belonging to eight countries located in three continents from 1953 fertile men with a time to pregnancy (TTP) of $<1$ year (Cooper et al., 2010). The new reference values 
for human semen characteristics were markedly lower than those previously reported (Esteves, Zini et al., 2012).

A series of reports has questioned the validity of these reference values because they categorised men who were previously considered infertile as fertile (Esteves, Hamada, Kondray, Pitchika, \& Agarwal, 2012; Haidl, 2011; Murray et al., 2012; Yerram, Sandlow, \& Brannigan, 2012). In addition, the new reference values were derived from data belonging to fertile men from Europe, Australia and North America, thus ignoring the vast majority of fertile men living in Africa, Asia, Middle East and South America. Recent controlled prospective studies confirmed regional differences between countries and continents as regards semen quality (Ellekilde Bonde, 2010; Vieira, 2013). Therefore, a major concern surrounded the ability of the new reference values for human semen to represent fertile men worldwide.

The objective of this study was to determine the reference values of standard semen parameters in a population of proven fertile Egyptian men. In order to avoid potential sources of bias and confounding factors, the following points were taken into consideration: (i) men's natural fertility was defined as the ability to initiate a recent spontaneous pregnancy with a TTP $\leq 12$ months; (ii) semen analysis was performed according to the guidelines of the 5 th edition of the WHO laboratory manual for examination of human semen (WHO,

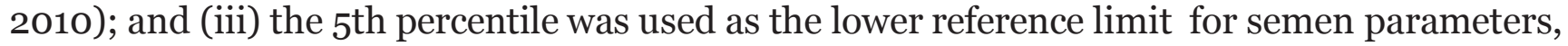
thus allowing to cross-match the results of this study with the reference values reported in the latest edition of the WHO in 2010.

\section{2 | Materials and methods}

2.1 $\mid$ Population and sample

This cross-sectional study was conducted in Assiut University Hospital, a central referral hospital located in Upper Egypt, between March 2014 and September 2016. The study was approved by the Institutional Research and Ethical Committees. Informed written consents were obtained from all participants. The study included fertile men whose wives were pregnant, at the time of recruitment, with TTP $\leq 12$ months. Time to pregnancy was defined as the number of months (or cycles) from starting regular unprotected sexual intercourse to achieving pregnancy.

For sample size calculation, the equation of $N=\left(z_{1-\alpha / 2}\right)^{2} P(1-P) / D^{2}$ was used as previously described (Kasiulevicius, Sapoka, \& Filipaviciute, 2006). In that equation, N, the minimum sample size required; ${ }^{Z_{1-\alpha}}$, the number of standard errors from the mean; $P$, the proportion of the best guess about the value of the proportion of interest; and $D$, the absolute precision required on either side of the proportion, or the distance; how close to the proportion of interest the estimate is desired to be. We considered confidence level at 95\%, $P=0.85, D=$ $0.05,(1-P)=0.15, \frac{Z_{1-4}}{2}=1.96$. The minimum number required to achieve the objective of the study was 196 participants. 
A total of 390 men were recruited to increase the statistical reliability of the results. Men with history of primary or secondary infertility; general or local medical conditions affecting fertility, for example recent febrile illness or epididymo-orchitis; or drugs reducing fertility such as chemotherapy or anti-androgens were excluded. Genital examination was carried out by a single andrologist.

\subsection{Semen analysis}

Standard semen analysis was performed according to the guidelines of the $5^{\text {th }}$ edition of the WHO laboratory manual for examination of human semen (WHO, 2010).

Participants were asked to deliver a semen sample into a sterile plastic container after a period of sexual abstinence of 2-7 days. The samples were left to liquefy in a $37^{\circ} \mathrm{C}$ incubator and were analysed within one hour of delivery. Standard procedures included macroscopic features (semen volume, viscosity and $\mathrm{pH}$ ); and microscopic parameters (sperm concentration, motility, vitality, morphology and seminal leucocyte counts). Hypo-osmotic swelling test was used for assessment of sperm vitality, and peroxidase-staining test was used for seminal leucocyte quantification. Leukocytospermia was considered at seminal leucocyte counts greater than one million peroxidase positive leucocytes per ml of semen (WHO, 2010).

To avoid inter-observer variability, all samples were examined by the same investigator and results were verified by a second observer. Two aliquots of thoroughly mixed semen samples were taken for replicate analysis. For each sample, replicate values were compared to check if they were acceptably close ( $<10 \%$ difference). If the difference was higher, two new aliquots were taken from the semen sample, two new preparations were made, and assessment was repeated.

\subsection{Statistical analysis}

Statistical analysis of the data was performed using SPSS version 21 program (SPSS Inc., Chicago, IL, USA). Quantitative data were presented as mean \pm standard deviations $(S D)$, and median ( $5^{\text {th }}$ and 95th percentiles). The lower reference values were considered at the $5^{\text {th }}$ percentiles. Spearman rank correlation test was applied to determine relationship between quantitative variables. $p$ value $<.05$ was set as statistically significant.

\section{3 | Results}

Out of 390 recruited fertile men, 240 (61.5\%) fulfilled the study's inclusion criteria, agreed to participate and were, therefore, enrolled in the study. The mean $\pm S D$ of age of participants was $33.8 \pm 0.5$ years (range 20-55 years). The mean $\pm S D$ of duration of marriage was 5.98 \pm 5.44 years. Clinically palpable varicocele was detected in 32 of 240 (13.3\%) of fertile men in this study ( 15 bilateral and 17 left side). The remaining 208 of 240 (86.7\%) of fertile men had no remarkable abnormality in their genital examination. 
All samples had normal viscosity (threading less than $2 \mathrm{~cm}$ ). Minimum and maximum values, mean $\pm S D$ and $5^{\text {th }}$, and 95th percentiles of seminal macroscopic (volume and $\mathrm{pH}$ ) and microscopic parameters (sperm concentration, motility, vitality, morphology and seminal leucocyte counts) in fertile Egyptian men are shown in Table 1. The 5th percentiles (95\% confidence interval) of semen parameters among fertile Egyptian men and those reported in the latest edition of the WHO laboratory manual for examination of human semen (WHO, 2010) are shown in Table 2. A demonstration of the mean values and the 5 th percentiles of semen parameters in the present, and in previous studies, is shown in Table 3.

When latest WHO (2010) lower reference values of normal semen parameters were applied to the 240 fertile men included in this study, $4 \%$ of the subjects had sperm concentrations lower than 15 million/ml, $2 \%$ had progressive motility less than $32 \%$ and $4.6 \%$ had less than $4 \%$ normal sperm forms. On the other hand, 101 of 240 (42\%) of fertile men, in this study, who were normozoospermic according to the WHO (2010), had at least one parameter below the reference values of 1999 WHO criteria. The differences in semen parameters of fertile men with and without clinically palpable varicoceles were not significant $(p>.05)$.

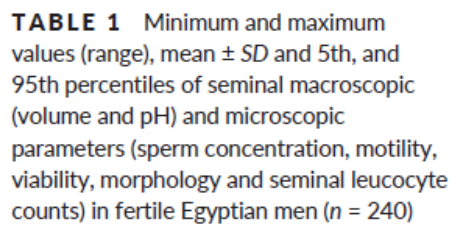

TABLE 1 Minimum and maximum values (range), mean $\pm S D$ and 5 th, and 95th percentiles of seminal macroscopic (volume and $\mathrm{pH}$ ) and microscopic parameters (sperm concentration, motility, viability, morphology and seminal leucocyte counts) in fertile Egyptian men ( $n=240$ )

\begin{tabular}{|c|c|c|c|}
\hline Semen parameters & $\begin{array}{l}\text { Range (minimum to } \\
\text { maximum) }\end{array}$ & Mean $\pm S D$ & $\begin{array}{l}\text { 5th and 95th } \\
\text { percentiles }\end{array}$ \\
\hline Semen volume (ml) & $0.4-7$ & $2.87 \pm 1.38$ & $1.5-5.5$ \\
\hline $\mathrm{pH}$ & $7-8$ & $7.3 \pm 0.22$ & $7.2-7.8$ \\
\hline $\begin{array}{l}\text { Sperm concentration } \\
\left(\times 10^{6} / \mathrm{ml}\right)\end{array}$ & $4-84$ & $37.26 \pm 19.38$ & $15-83$ \\
\hline $\begin{array}{l}\text { Total sperm count }\left(\times 10^{6} /\right. \\
\text { ejaculate })\end{array}$ & $16-336$ & $100.1 \pm 64.4$ & $30-216$ \\
\hline Total sperm motility (\%) & $30-80$ & $62.17 \pm 8.60$ & $50-75$ \\
\hline $\begin{array}{l}\text { Progressive sperm motility } \\
\text { (\%) }\end{array}$ & $15-70$ & $49.23 \pm 8.32$ & $40-60$ \\
\hline Sperm vitality (\%) & $30-85$ & $69.94 \pm 9.68$ & $62-80$ \\
\hline Sperm normal forms (\%) & $2-31$ & $10.34 \pm 7.04$ & $4-25$ \\
\hline $\begin{array}{l}\text { Seminal leucocytes }\left(\times 10^{6} /\right. \\
\mathrm{ml})\end{array}$ & $0.1-3$ & $0.44 \pm 0.44$ & $0.1-0.8$ \\
\hline
\end{tabular}




\begin{tabular}{|c|c|c|}
\hline Semen parameter & $\begin{array}{l}\text { WHO (2010) (5th } \\
\text { percentile) }\end{array}$ & $\begin{array}{l}\text { Fertile Egyptian } \\
\text { men }(n=240) \\
\text { (5th percentile) }\end{array}$ \\
\hline Volume (ml) & 1.5 & 1.5 \\
\hline $\mathrm{pH}$ & $7.2^{\mathrm{a}}$ & 7.2 \\
\hline $\begin{array}{l}\text { Sperm concentration } \\
\left(\times 10^{6} / \mathrm{ml}\right)\end{array}$ & 15 & 15 \\
\hline $\begin{array}{l}\text { Total sperm count }\left(\times 10^{6} /\right. \\
\text { ejaculate) }\end{array}$ & 39 & 30 \\
\hline Total sperm motility (\%) & 40 & 50 \\
\hline $\begin{array}{l}\text { Progressive sperm } \\
\text { motility (\%) }\end{array}$ & 32 & 40 \\
\hline Sperm vitality (\%) & 58 & 62 \\
\hline Sperm normal forms (\%) & 4 & 4 \\
\hline $\begin{array}{l}\text { Seminal leucocyte count } \\
\left(\times 10^{6} / \mathrm{ml}\right)\end{array}$ & $<1$ & 0.1 \\
\hline
\end{tabular}

\section{4 | Discussion}

The WHO considered men fertile when their partners had spontaneous pregnancy with TTP $\leq 12$ months (or cycles) following regular unprotected sexual intercourse (WHO, 2010). Time to pregnancy has been generally accepted to reflect the fertility of a couple because it correlates well with sperm quality and quantity as well as sexual activity (Olsen \& RamlauHansen, 2014). In the majority of cases involving male factor infertility, the diagnosis was based on abnormalities of semen quality with varying severity and poorly understood aetiology (Tomlinson, Kessopoulou, \& Barratt, 1999). Until the causes of male infertility are better understood, it is unlikely that any given descriptive test of sperm quality or sperm function will predict with absolute certainty that a man will be fertile or infertile in a given time period (Evenson et al., 1999).

Establishing reference values for semen parameters in fertile men is essential for accurate evaluation, counselling and treatment of men with male infertility (Redmon et al., 2013). In general, one-sided lower reference limits of semen parameters were used for discrimination between fertile and infertile men (WHO, 2010). However, there is controversy as to the cut-off values below which semen parameters are described as abnormal, and a diagnosis of male infertility could be given. Previous studies have proposed the 2.5th percentile (Cooper, Jockenhoevel, \& Nieschlag, 1991), 5th percentile (Andersen et al., 2002; Gao et al., 2007) or 10th percentile (Menkveld et al., 2001; van der Merwe, Kruger, Oehninger, \& Lombard, 2005) as lower reference values. The latest edition of the WHO laboratory manual for examination of human semen has determined the $5^{\text {th }}$ percentile as a lower reference limit that discriminates between fertile and infertile men based on their semen analyses results (WHO, 2010).

In the present study, the $5^{\text {th }}$ percentile of semen volume $(1.5 \mathrm{ml})$ was similar to that determined by the WHO 2010 and to the value reported in a recent study of semen 
parameters among American fertile men (Redmon et al., 2013). Lower cut-off values of semen volume were reported in recent studies on 1,213 fertile men in Guangdong Province, China $(1.3 \mathrm{ml})$ (Tang et al., 2015); and 792 fertile men from four large cities in Japan (1 ml)

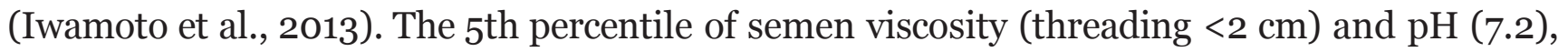
in the present study, were similar to those reported in the WHO laboratory manual in 2010. The latter has retained the cut-off values of semen viscosity and $\mathrm{pH}$ that were determined in the previous 4th edition of the WHO manual (WHO, 1999) due to lack of sufficient data to provide new reference cut-off values (WHO, 2010).

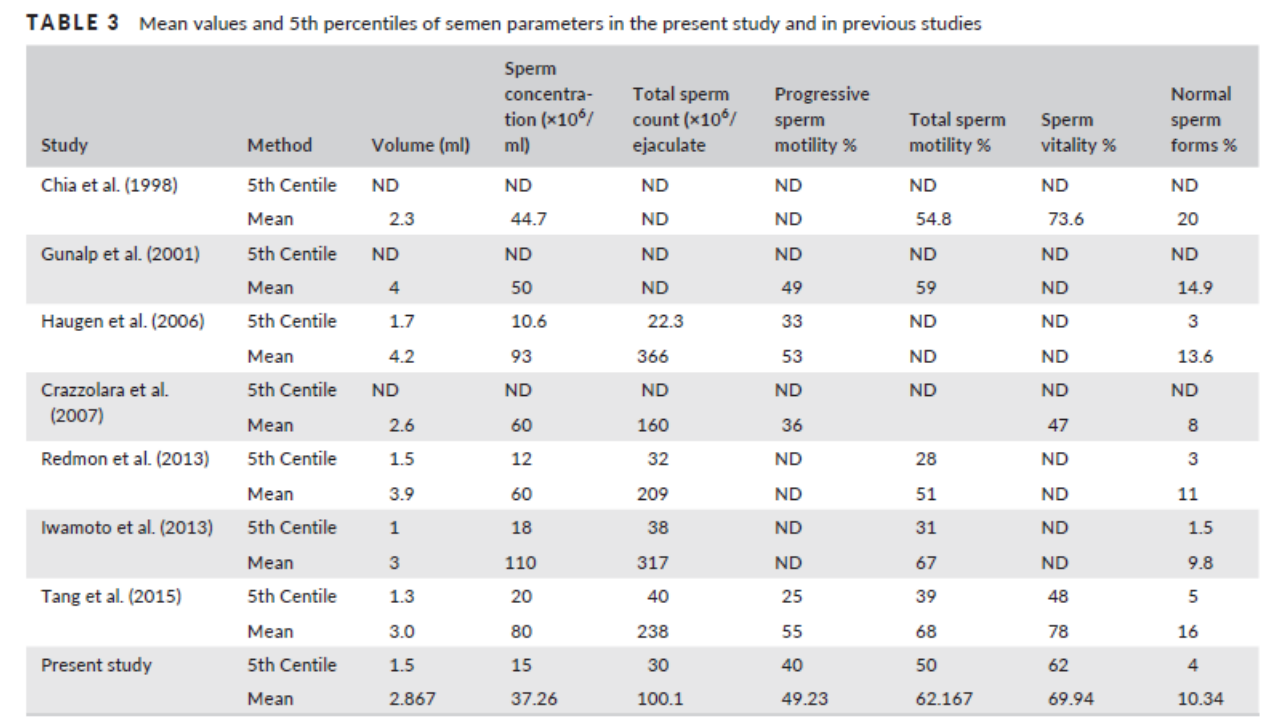

ND, not done.

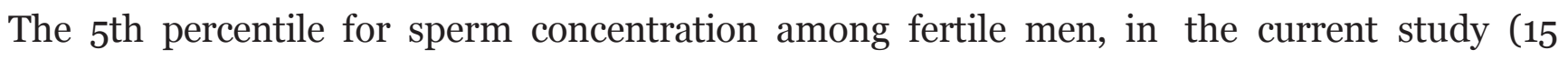
million/ml), was similar to the reference value determined by the WHO in 2010. A lower cutoff value of sperm concentration (12 million/ml) was reported among American fertile men (Redmon et al., 2013). Higher cut-off values of sperm concentrations were reported among Japanese fertile men (18 million/ml) (Iwamoto et al., 2013) and Chinese fertile men (20 million/ml) (Tang et al., 2015). The latest WHO manual has recommended to calculate and report the total sperm count as it provides a measure for the capability of the testis to produce spermatozoa as well as a test for the patency of the male genital tract (WHO, 2010). In the present study, the $5^{\text {th }}$ percentile of the total sperm count (30 million per ejaculate) did not match the value of 39 million per ejaculate, recorded by the $5^{\text {th }}$ edition (WHO, 2010), despite having similar cut-off values for semen volume and sperm concentration.

According to the WHO manual of 2010, the lower reference limits, for semen volume (1.5 $\mathrm{ml})$ and sperm concentration ( 15 million $/ \mathrm{ml}$ ), were $25 \%$ less than those reported in the previous 4th edition (WHO, 1999) ( $2 \mathrm{ml}$ and 20 million/ml respectively). However, the reference value for total sperm count (sperm concentration multiplied by volume) did not show a similar reduction (39 million per ejaculate in the WHO 2010 manual versus 40 million per ejaculate in 1999). The lower reference value for the total sperm count was 32 million spermatozoa/ejaculate in fertile American men (Redmon et al., 2013), 38 million spermatozoa/ejaculate in fertile Japanese men (Iwamoto et al., 2013) and 40 million 
spermatozoa/ejaculate in fertile Chinese men (Tang et al., 2015) respectively. Taken together, the lower reference value for total sperm count in fertile men from different geographical regions and ethnic backgrounds is a range between 30 and 40 million spermatozoa per ejaculate (mean $\pm S D=35.8 \pm 4.5$ ). The wide range of lower reference limits for total sperm count in fertile men may be attributed to many factors including methodological differences.

The 5 th percentile for progressive sperm motility, in the present study (40\%), was higher than the value of $32 \%$ reported by the $5^{\text {th }}$ edition of the WHO manual (WHO, 2010) and 25\% reported among fertile Chinese men (Tang et al., 2015). The 5th percentile of total sperm motility, in the present study (50\%), was higher than the value of $40 \%$ reported by the $5^{\text {th }}$ edition of the WHO manual (WHO, 2010), 39\% in the Chinese study (Tang et al., 2015) and $31 \%$ in the Japanese study (Iwamoto et al., 2013). The Chinese study used computer-assisted semen analysis (CASA) for sperm motility evaluation (Tang et al., 2015), and the Japanese study included $1.5 \%$ with a history of infertility and $12.6 \%$ with TTP greater than 12 months (Iwamoto etal., 2013).

The current WHO laboratory manual (WHO, 2010) determined the lower reference value for normal sperm forms as $4 \%$ based on the Tygerberg classification (strict criteria) that considers minimal morphological deviations as abnormal. Early reports found men with normal sperm forms between 5 and $14 \%$ to have better fertilisation rates than those with $4 \%$ or less (Coetzee, Kruger, \& Lombard, 1998). Strict criteria for assessment of sperm morphology were also correlated with the in vivo fertility potential (Eggert-Kruse et al., 1996). The 4\% lower reference limit (5th percentile) of normal sperm forms, in our study, matched the cutoff value of the WHO 2010 manual and was close to the $3 \%$ value among fertile American men (Redmon et al., 2013) and 5\% among fertile Chinese men (Tang et al., 2015).

Interestingly, $42 \%$ of normozoospermic fertile men, in this study, would be considered infertile according to the 4th edition in 1999 (WHO, 1999), with at least one parameter below the reference values of the later. It has been reported that $15.1 \%$ of men, who, on a previous analysis (according to the WHO manual of 1999), were deemed in the infertile range, would be classified at the fertile range using the WHO (2010) reference values (Murray et al., 2012).

\section{5 | Conclusions}

Proven fertile Egyptian men had higher reference values (5th percentiles) of sperm total motility, progressive motility and vitality, and lower reference values for total sperm counts as compared to those determined by the latest (2010) edition of WHO laboratory manual. Other semen parameters were identical to those defined by the WHO 2010 manual. Despite the cross-sectional nature of the study, it provided basic data of proven fertile men in Egypt, and the findings are interesting in many aspects.

First, these findings are in agreement with recent reports of a general trend towards lower reference values of sperm parameters. This trend was reflected in the latest edition of the WHO laboratory manual in 2010 and may indicate a decline in men's fertility potential in

\section{http://repository.uwc.ac.za}


recent years. Second, differences in sperm parameters among fertile men, in different studies including the current one, may be related to genetic, ethnic, geographical and environmental factors. It may also reflect, at least in part, a degree of methodological and inter-observer variability. Future studies adjusting for potential sources of bias and variability may help establish new cut-off values for sperm parameters that can accurately discriminate between fertile and infertile men. Adherence to TTP of less than 12 months as a time limit for fertility potential may help define the fertile population more precisely. Also, a longitudinal study of semen quality over time would be the ideal design to address the issue of establishing reference values of semen parameters of fertile men in a certain population.

\section{Acknowledgements}

The authors of this study would like to thank Dr Medhat El-Araby, MD, Assistant Professor, Department of Public Health; Faculty of Medicine, Assiut University, Egypt, for his help with statistical analysis.

\section{ORCID}

$\begin{array}{lr}\text { S. Ismail } & \text { http://orcid.org/oooo-ooo2-9607-9387 } \\ \text { R. Saleh } & \text { http://orcid.org/oooo-ooo3-0503-3533 } \\ \text { R. Henkel } & \text { http://orcid.org/oooo-ooo3-1128-2982 } \\ \text { A. Agarwal } & \text { http://orcid.org/oooo-0oo3-0585-1026 }\end{array}$ 


\section{References}

Andersen, A. G., Ziebe, S., Jorgensen, N., Petersen, J. H., Skakkebaek, N. E., \& Andersen, A. N. (2002). Time to pregnancy in relation to semen quality assessed by CASA before and after sperm separation. Human Reproduction, 17, 173-177. https://doi.org/10.1093/humrep/ 17.1.173

Chia, S. E., Tay, S. K., Lim, S. T. (1998). What constitutes a normal seminal analysis? Semen parameters of 243 fertile men. Human Reproduction, 13, 3394-3398.

Coetzee, K., Kruger, T. F., \& Lombard, C. J. (1998). Predictive value of normal sperm morphology: A structured literature review. Human Reproduction, 4, 73-82. https://doi.org/10.1093/humupd/4.1.73

Cooper, T. G., Jockenhoevel, F., \& Nieschlag, E. (1991). Variations in semen parameters from fathers. Human Reproduction, 6, 859-866. https://doi. org/10.1093/oxfordjournals.humrep.a137441

Cooper, T. G., Noonan, E., von Eckardstein, S., Auger, J., Baker, H. W., Behre, H. M., ... Vogelsong, K. M. (2010). World Health Organization reference values for human semen characteristics. Human Reproduction Update, 16, 231-245. https://doi.org/10.1093/ humupd/dmpo48

Crazzolara, S., Wunder, D., Nageli, E., Bodmer, C., Graf, S., Birkhauser, M. H. (2007). Semen parameters in a fertile Swiss population. Swiss Medical Weekly, 137, 166-172.

Eggert-Kruse, W., Schwarz, H., Rohr, G., Demirakca, T., Tilgen, W., \& Runnebaum, B. (1996). Sperm morphology assessment using strict criteria and male fertility under in vivo conditions of conception. Human Reproduction, 11, 139-146. https://doi.org/10.1093/oxfordjournals. humrep.a019007

Ellekilde Bonde, J. P.(2010). Semen analysis from an epidemiologic perspective. Asian Journal of Andrology, 12, 91-94. https://doi.org/10.1038/ aja.2008.49

Esteves, S. C. (2014). Clinical relevance of routine semen analysis and controversies surrounding the 2010 World Health Organization criteria for semen examination. International Brazilian Journal of Urology, 4O, 443-453.

Esteves, S. C., Hamada, A., Kondray, V., Pitchika, A., \& Agarwal, A. (2012). What every gynecologist should know about male infertility: An update. Archives of Gynecology and Obstetrics, 286, 217-229. https://doi. org/10.1007/s00404-012-2274-x

Esteves, S. C., Zini, A., Aziz, N., Alvarez, J. G., Sabanegh, E. S. Jr, \& Agarwal, A. (2012). Critical appraisal of World Health Organization's new reference values for human semen characteristics and effect on diagnosis and treatment of subfertile men. Urology, 79, 16-22. https://doi. org/10.1016/j.urology.2011.08.003

Evenson, D. P., Jost, L. K., Marshall, D., Zinaman, M. J., Clegg, E., Purvis, K., ... Claussen, O. P. (1999). Utility of sperm chromatin structure assay as a diagnostic and prognostic tool in the human fertility clinic. Human Reproduction, 14, 1039-1049. https://doi.org/10.1093/ humrep/14.4.1039

Gao, J., Gao, E. S., Yang, Q., Walker, M., Wu, J. Q., Zhou, W. J., \& Wen, S. W. (2007). Semen quality in a residential, geographic and age representative sample of healthy Chinese men. Human Reproduction, 22, 477-484. https://doi.org/10.1093/humrep/del383 
Gunalp, S., Onculogulo, C., Gurgan, T., Kruger, T. F., Lombard, C. J. (2001). A study of semen parameters with emphasis on sperm morphology in a fertile population: an attempt to develop clinical thresholds. Human Reproduction, 16,110-114.

Haidl, G. (2011). New WHO-reference limits-revolution or storm in a teapot? Asian Journal of Andrology, 13, 208-211. https://doi.org/10.1038/ aja.2010.156

Haugen, T. B., Egeland, T., Magnus, O. (2006). Semen parameters in Norwegian fertile men. Journal of Androlology, 27, 66-71.

Iwamoto, T., Nozawa, S., Yoshiike, M., Namiki, M., Koh, E., Kanaya, J., ... Jørgensen, N. (2013). Semen quality of fertile Japanese men: A cross-sectional population-based study of 792 men. British Medical Journal, 3, 223-233.

Kasiulevicius, V., Sapoka, V., \& Filipaviciute, R. (2006). Sample size calculation in epidemiological studies. Gerontology, 7, 225-231.

Menkveld, R., Wong, W. Y., Lombard, C. J., Wetzels, A. M. M., Thomas, C. M. G., Merkus, H. M. W. M., \& Theunissen, R. P. M. (2001). Semen parameters, including WHO and strict criteria morphology, in a fertile and sub-fertile population: An effort towards standardization of in vivo thresholds. Human Reproduction, 16, 1165-1171. https://doi. org/10.1093/humrep/16.6.1165

van der Merwe, F. H., Kruger, T. F., Oehninger, S. C., \& Lombard, C. J. (2005). The use of semen parameters to identify the subfertile male in the general population. Gynecologic and Obstetric Investigation, 59, 86-91.

Murray, K. S., James, A., McGeady, J. B., Reed, M. L., Kuang, W. W., \& Nangia, A. K. (2012). The effect of the new 2010 World Health Organization criteria for semen analyses on male infertility. Fertility and Sterility, 98, 1428-1431. https://doi.org/10.1016/j. fertnstert.2012.07.1130

Olsen, J., \& Ramlau-Hansen, C. H. (2014). Epidemiologic methods for investigating male fecundity. Asian Journal of Andrology, 16, 17-22.

Redmon, J. B., Thomas, W., Ma, W., Drobnis, E. Z., Sparks, A., Wang, C., ... Swan, S. H. (2013). Semen parameters in fertile US men: The Study for Future Families. Andrology, 6, 806-814. https://doi. org/10.1111/j.2047-2927.2013.00125.x

Saleh, R. A., Agarwal, A., Nelson, D. R., Nada, E. A., El-Tonsy, M. H., \& Alvarez, J. G. (2002). Increased sperm nuclear DNA damage in normozoospermic infertile men: A prospective study. Fertility and Sterility, $78, \quad 313-318$. https://doi.org/10.1016/Soo15-0282(02)03219-3

Tang, Y. G., Tang, L. X., Wang, Q. L., Song, G., Jiang, Y. J., Deng, S. M., ... Qin, W. B. (2015). The reference values for semen parameters of 1213 fertile men in Guangdong Province in China. Asian Journal of Andrology, 17, 298-303. https://doi.org/10.4103/1008-682X.143251

Tomlinson, M. J., Kessopoulou, E., \& Barratt, C. L. R. (1999). The value of diagnostic and prognostic value of traditional semen parameters. Journal of Andrology, 20, 588-593.

Vieira, M. (2013). New World Health Organization reference values for semen analysis: Where do we stand? Einstein (Sao Paulo), 1, 263-264. https://doi.org/10.1590/S1679-45082013000200023 
World Health Organization (1999). Laboratory manual for the examination of human semen and sperm-cervical mucus interaction (4th ed.). Cambridge, UK: Cambridge University Press.

World Health Organization (2010). WHO laboratory manual for the examination and processing of human semen (5th ed.). Geneva, Switzerland: WHO Press.

Yerram, N., Sandlow, J. I., \& Brannigan, R. E. (2012). Clinical implications of the new 2010 WHO reference ranges for human semen characteristics. Journal of Andrology, 33, 289-290. https://doi.org/10.2164/jandrol.111.014472 